\title{
PENGARUH KUALITAS PELAYANAN DAN LOKASI TERHADAP LOYALITAS PELANGGAN HOTEL BINTANG DUA DI KOTA BATAM
}

\author{
Wasiman $^{1}$, Frangky Slitonga ${ }^{2}$, Agung Edy Wibowo ${ }^{3}$ \\ Universitas Putera Batam ${ }^{1}$, Universitas Karimun ${ }^{2}$, STIKes Awal Bros Batam ${ }^{3}$ \\ (Wasiman903@gmail.com, frangkyka@gmail.com, edywbw.11@gmail.com)
}

\begin{abstract}
Abstrak
Perkembangan Industri perhotelan di kota Batam berkembang dengan begitu cepat dengan dicanagkanya Batam menjadi salah satu program destiniasi wisata oleh pemerintah pusat sehingga menimbulkan efek terhadap persahaan swasta untuk berlomba lomba membangun hotel sehingga persaingan terhadap kualitas pelayanan secara otomatis semakin meningkat. Dalam penelitian ini metode yang digunakan dalam penelitian ini adalah dengan cara membagikan kuesioner kepada pelanggan pelanggan hotel bintang dua di Kota Batam . Jumlah sampel dalam penelitian ini sebanyak 111 sampel. Hasil Uji R, dapat dilihat bahwa nilai Adjsuted $R$ Square sebesar 0,730, atau sebesar $73.70 \%$. Hal ini berarti variabel loyalitas pelanggan dapat dijelaskan oleh variabel kualitas pelayanan, variabel lokasi sebesar $73.0 \%$, sedangkan sisanya sebesar $27.0 \%$ dipengaruhi oleh faktor lain yang tidak disertakan dalam penelitian ini. Hasil Uji F menyimpulkan bahwa variabel kualitas pelayanan dan lokasi berpengaruh terhadap loyalitas pelanggan Hotel Bintang dua di Kota Batam
\end{abstract}

Keywords: Quality of Service, Location and Customer Loyalty

\section{PENDAHULUAN}

Perkembangan industri jasa di kota Batam berkembang dengan sangat cepat seiring dengan membaiknya perekonomian di Kota Batam, sehingga memunculkan persaingan yang sedemikan ketat antara perusahaan yang bergerak dibidang jasa.

Alasan pengambilan obyek bintang dua dijdikan penelitian tentunya sangat menarik dikarenakan hotel bintang dua pasti memiliki keterbatasan dalam hal fasilitas disamping itu hotel bintang dua biasanya lokasi jauh masuk ke dalam sehingga ini yang menyebabkan kesulitan yang dialami oleh pelanggan. Kesulita lain yang dialami oleh pelanggan adalah biasanya berhubungan dengan kualitas pelayanan hal ini juga menjadi semakin menarik karena dalam kualitas pelayanan hotel bintang dua belum memiliki standar kualitas seperti hotel htel bintang tiga bahkan hotel bintang empat.

\subsection{Identifikasi Masalah}

Berdasarkan uraian mengenai latar belakang penelitian yang dikemukakan diatas, maka identifikasi masalah yang muncul adalah:

1. Kualitas pelayanan yang masih belum standar sehingga kualitas pelayanan masih bersifat individu.

2. Lokasi yang jauh masuk ke dalam artinya tidak dipinggir jalan besar dan jalan utama.

3. Belum ada standar kualitas pelayanan 


\subsection{Perumusan Masalah} berikut:

Berdasarkan identifikasi masalah tersebut di atas dapat dirumuskan masalah sebagai

1. Apakah kualitas pelayanan berpengaruh terhadap loyalitas pelanggan hotel bintang dua di Kota Batam?

2. Apakah lokasi berpengaruh terhadap loyalitas pelanggan hotel bintang dua di Kota Batam?

3. Apakah Kualitas Pelayanan, dan lokasi berpengaruh terhadap loyalitas pelanggan hotel bintang dua di Kota Batam?

\subsection{Tujuan Penelitian}

Adapun tujuan yang dilakukan penelitian ini adalah :

1. Untuk mengetahui pengaruh kualitas pelayanan terhadap loyalitas Hotel Bintang dua di Kota Batam

2. Untuk mengetahui pengaruh Lokasi terhadap loyalitas pelanggan Hotel Bintang dua di Kota Batam

3. Untuk mengetahui pengaruh Kualitas Pelayanan, dan lokasi terhadap loyalitas pelanggan hotel bintang dua di Kota Batam

\section{TINJAUAN PUSTAKA}

\subsection{Kualitas Pelayanan}

Kualitas pelayanan dapat didefinisikan sebagai :The extent of discrepancy between customers expactations or desire and their perceptions (Widjaja, 2009) Dari pernyataan ini dikemukakan bahwa kualitas pelayanan yang diterima konsumen dinyatakan besarnya perbedaan antara harapan atau keinginan konsumen dengan tingkat persepsi mereka. Kualitas pelayanan sebagai seberepa jauh perbedaan antara kenyataan dan harapan pelanggan atas layanan yang mereka terima atau diperoleh (Wibowo, 2017)

\section{Indikator-Indikator Kualitas Pelayanan}

Menurut (Tjiptono, 2008) menyatakan ada lima dimensi kualitas layanan adalah

1. Keandalan (Reliabilitas), yakni kemampuan memberikan layanan yang dijanjikan dengan segera, akurat dan memuaskan.

2. Ketanggapan (Responsivitas), yaitu keinginan dan kesediaan para karyawan untuk membantu para pelanggan dan memberikan layanan yang tanggap.

3. Jaminan (Assurance), mencakup pengetahuan, kompetisi, kesopanan dan sifat dapat dipercaya yang dimilki para karyawan : bebas dari bahaya fisik, resiko atau keraguraguan.

4. Empati (Empathy), meliputi kemudahaan dalam menjalin hubungan, komunikasi yang efektif, perhatian personal, dan pemahaman atas kebutuhan individual para pelanggan.

5. Bukti Fisik (Tangibles), meliputi fasilitas fisik, perlengkapan, karyawan dan sarana komunikasi.

\subsection{Lokasi}

Menurut (Kotler dan Amstrong, 2011) menyatakan bahwa place (tempat) atau lokasi, yaitu berbagai kegiatan perusahaan untuk membuat produk yang dihasilkan atau dijual 
terjangkau dan tersedia bagi pasar sasaran. Lokasi atau tempat merupakan gabungan antara lokasi dan keputusan atas saluran distribusi, dalam hal ini berhubungan dengan bagaimana cara penyampaian kepada para pelanggan dan dimana lokasi yang strategis (Dharmmesta, 2010).

\subsection{Indikator Lokasi}

Menurut (Hurriyati,2016: 87) ada beberapa indikator lokasi yaitu:

1. Lokasi menguntungkan

2. Lingkungan yang mendukung

3. Lingkungan sesuai harapan

4. Akses Menuju lokasi

5. Kenyamanan Lokasi

\subsection{Loyalitas Pelanggan}

Menurut (Lovelock dan Jochen,2014: 338), loyalitas pelanggan yaitu kesediaan pelanggan untuk terus menerus berlangganan pada sebuah persuahaan dalam jangka panjang, dengan membeli dan menggunakan barang dan jasanya secara berulang-ulang dan lebih baik lagi secara eksklusif, dan dengan sukarela merekomendasikannya kepada pihak lain.

Indikator Loyalitas Pelanggan

Indikator Loyalitas Pelanggan

Indicator dari loyalitas yang kuat adalah (Japarianto, 2017: 36) yaitu:

1. Say Positive Thing

2. Recommend Friends

3. Continue Purchasing

\subsection{Kerangka Pemikiran}

Kerangka pemikiran penelitian ini menggambarkan hubungan diantara variabel independen, dalam hal ini adalah kualitas pelayanan (X1),) lokasi (X2) terhadap variabel dependen yaitu loyalitas pelanggan(Y).

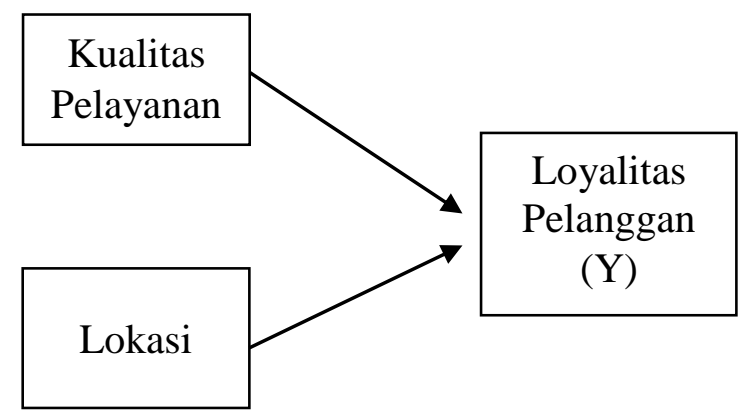

\section{Hipotesis}

Hipotesis penelitian sebagai berikut:

H1: Kualitas pelayanan berpengaruh signifikan terhadap loyali pelanggan Pada hotel bintang dua di Kota Batam. 
H2: Lokasi berpengaruh signifikan terhadap loyalitas pelanggan Pada hotel bintang dua di kota Batam.

H3: Kualitas pelayanan dan lokasi berpengaruh signifikan terhadap loyalitas pelanggan.

\section{METOGOLOGI PENELITIAN}

Penelitian ini menggunakan metode penelitian kuantitatif jenis metode survey. Menurut (Wibowo, 2013) Metode kuantitatif adalah metode penelitian dengan berlandaskan atas filsafat posiitivisme. Metode ini digunakan pada penelitian dengan populasi ataupun sampel yang tertentu, pengumpulan semua data dilakukan dengan instrumen penelitian, analisis data bersifat kuantitatif/statistik yang bertujuan menguji hipotesis yang telah ditetapkan. Menurut Sugiyono (2015:38) operasional variabel penelitian merupakan suatu atriibut atau sifat ataupun nilai dari suatu kegiatan yang memiliki variasi tertentu yang telah ditetapkan peneliti untuk dipelajari dan menarik suatu kesimpulan.

$$
n=\frac{N}{1+N \alpha^{2}}
$$

\section{Rumus Slovin}

(Sanusi, 2011:101)

$\mathrm{n}=\frac{155}{1+155(0,05)^{2}}$

$\mathrm{n}=\frac{155}{0.05}$

$\mathrm{n}=110,7$ dibulatkan menjadi 111 Orang

Proses dalam mengumpulkan data merupakan prosedur sistematis dan memenuhi standar untuk memperoleh data yang diperlukan. Data merupakan kumpulan dari informasi yang dapat digunakan untuk proses anallisa lebih lanjut. Pada penelitian ini peneliti menggunakan data primer dan sekunder. Data primer merupakan pemberi data bagi peneliti sebagai pengumpul data. Pada penelitian ini pengumpulan data primer dilakukan dengan penyebarkan angket kuesioner secara langsung terhadap pelanggan hotel bintang dua di Kota Batam.

Skala Likert merupakan skala pengukur pada peneliti ini. Dapat pengukur persepsi, suatu sikap, ataupun pendapat yang berasal dari seseorang ataupun kelompok mengenai suatu fenomena sosial yang terjadi (Sugiyono, 2015:93).

Variabel yang diukur menggunakan skala likert diukur serta dijabarkan menjadi indikator-indikator variabel penelitian. Indikator akan dijadikan sebagai titik tolak dalam penyusunan item-item instumen berupa pernyataan-pernyataan. Jawaban berupa pernyataan telah ditentukan oleh peneliti dengan gradasi dari yang sangat positif sampai gradasi yang sangat negatif. 
Tabel 3.2 Skala Likert

\begin{tabular}{|l|c|}
\hline \multicolumn{1}{|c|}{ Pernyataan } & Skor \\
\hline Sangat Setuju (SS) & 5 \\
\hline Setuju (ST) & 4 \\
\hline Ragu-ragu (RG) & 3 \\
\hline Tidak Setuju (TS) & 2 \\
\hline Sangat Tidak Setuju (STS) & 1 \\
\hline
\end{tabular}

Sumber: Sugiyono (2014: 94 )

Menurut Sugiyono (2012:348) instrumen yang reliabel adalah instrumen yang bila dipergunakan bebberapa kali untuk mengukur obyek yang sama tetap memberikan hasil yang sama pula. Uji reliabilitas dilakukan untuk mengetahui konsistensi serta ketepatan pengukuran pada objek sama apabila pengukuran dilakukan berulang kali dengan instrumen yang sama. Uji reliabilitas dapat diukur secara bersama-sama terhadap seluruh butir pernyataan. Uji statistic Cronbach Alfa ( $\alpha$ ) digunakan untuk menguji tingkat reliabel jika nilai Cronbach Alfa $>0,60$. Pengujian reliabilitas untuk setiap variabel pada penelitian ini dilakukan dengan Cronbach Alfacoefficient menggunakan bantuan program SPSS 25.(Wibowo, 2012).

\section{HASIL DAN PEMBAHASAN}

Pengujian kuesioner digunakan untuk mengukur keadaan responden atau sebuah pengujian untuk membuktikan valid atau tidak valid pernyataan kuesioner dapat dilakukan dengan angka koefisien korelasi product moment person dengan signifikansi sebesar 0,05 (Sanusi, 2012)

Tabel 4.1

Hasil Uji Validitas Kualitas Pelayanan (X1)

\begin{tabular}{cccc}
\hline No & R hitung & R tabel & Keterangan \\
\hline X1.1 & 0,755 & 0,131 & Valid \\
X1.2 & 0,651 & 0,131 & Valid \\
X1.3 & 0,645 & 0,131 & Valid \\
X1.4 & 0,710 & 0,131 & Valid \\
X1.5 & 0,817 & 0,131 & Valid \\
\hline
\end{tabular}

Sumber : Hasil pengolahan SPSS versi 25 (2020)

Tabel 4.2

Uji Validitas Lokasi (X2)

\begin{tabular}{cccc}
\hline No & R hitung & R tabel & Keterangan \\
\hline X2.1 & 0,723 & 0,131 & Valid \\
X2.2 & 0,875 & 0,131 & Valid \\
X2.3 & 0,710 & 0,131 & Valid \\
X2.4 & 0,674 & 0,131 & Valid \\
X2.5 & 0,758 & 0,131 & Valid \\
\hline
\end{tabular}

Sumber : Hasil pengolahan SPSS versi 25 (2020) 
Tabel 4.3

Uji Validitas Loyalitas Pelanggan (Y)

\begin{tabular}{cccc}
\hline No & R hitung & R tabel & Keterangan \\
\hline Y1.1 & 0763 & 0,131 & Valid \\
Y1.2 & 0,781 & 0,131 & Valid \\
Y1.3 & 0,715 & 0,131 & Valid \\
\hline
\end{tabular}

Sumber : Hasil pengolahan SPSS versi 25 (2020)

Berdasarkan tabel diatas dapat diuraikan:

1. Tabel 1 variabel kualitas pelayanan dapat dikaetahui $\mathrm{R}$ hitung lebih besar dari $\mathrm{R}$ tabel maka valid.

2. Tabel 2 variabel lokasi dapat diketahui $\mathrm{R}$ hitung lebih besar dari $\mathrm{R}$ tabel maka valid.

3. Tabel 3 variabel loyalitas pelanggan dapat dikaetahui $\mathrm{R}$ hitung lebih besar dari $\mathrm{R}$ tabel maka disimpulkan valid.

\subsection{Hasil Uji Realibilitas}

Uji ini dilakukan untuk mengetahui sejauh mana hasil pengukuran relatif konsisten apabila dilakukan secara berualang atau lebih dari satu kali. Kriteria uji reliabilitas cronbach's alpha harus lebih besar dari 0,60.

Tabel 4.4

Hasil Uji Realibilitas

\begin{tabular}{lccc}
\multicolumn{1}{c}{ Variabel } & $\begin{array}{c}\text { Hasil Korelasi Produk } \\
\text { Moment }\end{array}$ & Kriteria & Interpretasi \\
\hline Kualitas Pelayanan (X1) & 0,810 & $>0,60$ & Realiabel \\
Lokasi (X2) & 0,845 & $>0,60$ & Realiabel \\
Loyalitas Pelanggan (Y) & 0,811 & $>0,60$ & Realiabel \\
\hline
\end{tabular}

Sumber : Hasil pengolahan SPSS versi 25 (2019)

Berdasarkan tabel diatas dapat dijelaskan :

1. Variabel Kualitas pelayanan (X1) 0,810>0,60 menunjukkan bahwa 5 (lima) pernyataan yang diukur adalah reliabel.

2. Variabel Lokasi (X2) 0,845 >0,60 menunjukkan bahwa dari 5 (tlima) pernyataan yang diukur adalah reliabel.

3. Variabel loyalitas pelanggan (Y) 0,811 > 0,60 menunjukkan bahwa 5 (lima) pernyataan yang diukur adalah reliabel.

Uji normalitas digunakan untuk melihat apakah dalam model regresi variabel dependen dan independen memiliki distribusi normal atau tidak. Model yang paling baik adalah distribusi data normal atau mendekati normal. 


\subsection{Hasil Uji Kolmogrov-Smirnov}

Tabel 4.5

Hasil Uji Kolmogorov-Smirnov

\begin{tabular}{|c|c|c|}
\hline \multicolumn{3}{|c|}{ One-Sample Kolmogorov-Smirnov Test } \\
\hline & & Unstandardized Residual \\
\hline \multicolumn{2}{|l|}{$\mathrm{N}$} & 111 \\
\hline \multirow{2}{*}{$\begin{array}{l}\text { Normal } \\
\text { Parameters }\end{array}$} & Mean & 0,0000000 \\
\hline & Std. Deviation & 2,31556388 \\
\hline Most Extreme & Absolute & 0,054 \\
\hline \multirow[t]{2}{*}{ Differences } & Positive & 0,038 \\
\hline & Negative & $-0,054$ \\
\hline \multirow{2}{*}{\multicolumn{2}{|c|}{$\begin{array}{l}\text { Test Statistic } \\
\text { Asymp. Sig. (2-tailed) }\end{array}$}} & 0,054 \\
\hline & & $0,200^{\mathrm{c}, \mathrm{c}}$ \\
\hline a. Tes diistribu & Jormal. & \\
\hline
\end{tabular}

Dilihat dari hasil pengujian metode Kolmogorov-Smirnov tabel 4.5 diketahu nilai signifikansi (Asymp.Sig 2-tailed) sebesar 0,200. Nilai signifikansi ini telah melebihi 0,05 $(0,200>0,05)$ maka nilai data dalam penelitian ini terdistribusi normal.

\subsection{Hasil Uji Multikolineritas}

\section{Tabel 4.6}

Hasil Uji Multikolineritas

\begin{tabular}{cccc}
\hline \multirow{2}{*}{ Variabel } & \multicolumn{2}{c}{ Collinearity Statistics } & Kesimpulan \\
& Tolerance & VIF & Tidak terjadi Multikolineritas \\
Kualitas Pelayanan (X1) & 0,554 & 1,136 & Tidak terjadi Multikolineritas \\
\hline Lokasi (X2) & 0,554 & 1,136 &
\end{tabular}

Sumber : Hasil Pengolahan SPSS versi 25 (2019)

Tabel 4.6 menunjukkan hasil perhitungan nilai tolerance tidak ada variabel independen yang nilai Tolerancenya $<0.10$ dengan nilai tolerance masing-masing variabel independen kualitas pelayanan (X1) sebesar 0,554 dan lokasi (X2) bernilai 0,554. Sementara nilai Variance Inflation Factor (VIF) juga menunjukkan hal serupa yaitu tidak adanya nilai VIF dari variabel independen yang memiliki nilai VIF lebih dari 10 dengan nilai VIF masingmasing variabel independen bernilai 1,136 untuk kualitas pelayanan (X1) dan bernilai sama dengan variabel lokasi (X2) senilai 1,136. 


\subsection{Uji Pengaruh Analisis Regresi Berganda.}

Tabel 4.7

Hasil Uji Regresi Linier Berganda

\begin{tabular}{ccccccc}
\hline & & B & Std. Error & Beta & T & Sig. \\
\hline & (Constant) & 2,395 & 1,123 & & 2,311 & 0,022 \\
1 & $\begin{array}{c}\text { Kualitas Pelayanan } \\
(\mathrm{X} 1)\end{array}$ & 0,305 & 0,080 & 0,178 & 2,439 & 0,000 \\
& Lokasi (X2) & 0,548 & 0,072 & 0,699 & 6,024 & 0,000 \\
\hline
\end{tabular}

Sumber : Hasil Pengolahan SPSS versi 25 (2020)

Dari tabel diatas dapat dijelaskan :

1. Nilai konstanta $\beta=2,395$ menunjukkan bahwa terdapat pengaruh yang positif dari kualitas pelayanan (X1) dan lokasi (X2). Jika variabel kualitas pelayanan dan variabel lokasi sebesar $=0$, maka nilai variabel dari loyalitas pelanggan sebesar 2,395.

2. Koefisien regresi variabel kualitas pelayanan (X1) terhadap variabel loyalitas pelanggan (Y) Hasil ini menunjukkan bahwa jika nilai kualitas pelayanan semakin tinggi maka akan meningkatkan loyalitas pelanggan sebesar sebesar 0,305 dengan tingkat signifikan sebesar 0,000 .

3. Koefisien regresi variabel lokasi (X2) terhadap variabel loyalitas pelanggan (Y) hotel bintang dua di kota batam semakin tinggi maka akan meningkatkan loyalitas pelanggan sebesar 0,558 dengan tingkat signifikan sebesar 0,000.

\subsection{Analisis Determinasi $\left(\mathbf{R}^{2}\right)$}

Tabel 4.8

Hasil Uji Analisis Koefesien Determinasi

\begin{tabular}{|c|c|c|c|c|}
\hline Model & $\mathbf{R}$ & R Square & Adjusted R Square & $\begin{array}{l}\text { Std. Error of the } \\
\text { Estimate }\end{array}$ \\
\hline 1 & $.847^{\mathrm{a}}$ & 0,754 & 0,730 & 2,326 \\
\hline
\end{tabular}

Sumber : Hasil Pengolahan SPSS versi 25 (2020)

Tabel 4.8 menunjukkan nilai adjusted $\mathrm{R}$ sebesar 0,730 yang berarti korelasi antara variabel kualitas pelayanan (X1), dan lokasi (X2) terhadap variabel loyalitas pelanggan (Y) adalah sebesar 0,730 atau $73,0 \%$. Artinya menunjukkan nilai $\mathrm{R}$ Square sebesar 0,730 loyalitas pelanggan dapat dijelaskan oleh variable kualitas pelayanan dan variable lokasi sebesar $73 \%$ sedangkan sisasnya dipengaruhi oleh variable lain diluar penelitian ini

\subsection{Hasil Uji T (Parsial)}

Uji parsial sebagaimana telah dijelaskan pada metodologi penelitian adalah uji yang digunakan untuk mengetahui dan menganalisis hubungan masing-masing variabel bebas dengan variabel terikatnya. 


\begin{tabular}{|c|c|c|c|c|c|c|}
\hline & \multicolumn{6}{|c|}{$\begin{array}{c}\text { Tabel } 4.9 \\
\text { Hasil Uji T (Parsial) }\end{array}$} \\
\hline & & B & Std. Error & Beta & $\mathbf{T}$ & Sig. \\
\hline \multirow{3}{*}{1} & (Constant) & 2,395 & 1,123 & & 2,311 & 0,022 \\
\hline & $\begin{array}{c}\text { Kualitas } \\
\text { Pelayanan (X1) }\end{array}$ & 0,305 & 0,080 & 0,178 & 2,439 & 0,000 \\
\hline & Lokasi (X2) & 0,548 & 0,072 & 0,699 & 6,024 & 0,000 \\
\hline
\end{tabular}

Sumber : Hasil Pengolahan SPSS versi 25 (2019)

Hasil Uji T dapat dijelaskan bahwa:

a. Variabel kualitas pelayanan (X1) ditunjukkan dengan nilai t hitung sebesar 2,439 > t tabel $=1,971$ dan memiliki nilai signifikansi $0,000<0,05$. Artinya Ho dinyatakan ditolak dan Ha diterima. Dengan demikian kualitas pelayanan dinyatakan memiliki pengaruh yang signifikan terhadap loyalitas pelanggan . Hipotesis pertama penelitian ini dinyatakan diterima.

b. Variabel lokasi (X2) ditunjukkan dengan nilai t hitung sebesar 6,024 $>\mathrm{t}$ tabel $=1,971$ dan nilai signifikansi $0,000<0,05$ yang artinya Ho tidak diterima dan Ha diterima. Dengan demikian dinyatakan lokasi memiliki pengaruh signifikan terhadap loyalitas pelanggan. Hipotesis kedua penelitian ini dinyatakan diterima.

\subsection{Hasil Uji F (Simultan)}

Tabel 4.10

Hasil Uji F (Simultan)

\begin{tabular}{ccccccc}
\hline \multicolumn{2}{c}{ Model } & $\begin{array}{c}\text { Sum of } \\
\text { Squares }\end{array}$ & df & $\begin{array}{c}\text { Mean } \\
\text { Square }\end{array}$ & F & Sig. \\
\hline \multirow{3}{*}{1} & Regression & 1337,945 & 2 & 618,973 & 112,899 & $.000^{\mathrm{b}}$ \\
& Residual & 1106,413 & 109 & 4,410 & & \\
\hline & Total & 2444,358 & 111 & & & \\
\hline
\end{tabular}

Sumber : Hasil Pengolahan SPSS versi 25 (2020)

Pengujian hipotesis ditunjukkan dengan $\alpha=5 \%$. Diketahui pada tabel 4.10 nilai $\mathrm{F}$ hitung $=112,899$ sedangkan nilai $\mathrm{F}$ tabel $=3,04$. Dengan demikian $\mathrm{F}$ hitung $>\mathrm{F}$ tabel, dan probabilitas (sig) sebesar $0,000<0,05$. Maka secara simultan kualitas pelayanan dan lokasi bersama-sama berpengaruh signifikan terhadap loyalitas pelannggan. Maka hipotesis ketiga penelitian ini dinyatakan diterima.

\subsection{Pembahasan}

Berdasarkan penelitian yang telah diselesaikan, berikutt merupakan hasil yang diperoleh dari kegiatan penelitian ini :

1. Pengaruh kualitas pelayanan terhadap loyalitas pelanggan hotel bintang dua di Kota

Batam.

Dari hasil pengujian dapat diketahui bahwa variabel kualitas pelayanan (X1) dengan nilai koefisien sebesar 0,305 memiliki pengaruh secara positif dan memiliki hubungan yang signifikan terhadap loyalitas pelanggan (Y). Hal ini diketahui dari nilai signifikan 0,000 > 0,05 (nilai alpha). Hasil uji t hitung 2,311 > t tabel 1,971 menunjukkan bahwa variabel 
kualitas pelayanan (X1) berpengaruh secara positif dan signifikan terhadap loyalitas pelanggan (Y).

2. Lokasi berpengaruh terhadap loyalitas pelanggan hotel bintang dua di kota Batam.

Berdasarkan pada hasil pengujian yang telah dilakukan diketahui bahwa variabel lokasi (X2) dengan nilai koefisien sebesar 0,548 berpengaruh secara positif dan memiliki hubungan yang signifikan terhadap loyalitas pelanggan (Y). Hal ini terlihat dari nilai signifikan 0,000 > 0,00 (nilai alpha). Hasil uji t hitung 6,024> t tabel 1,971 menunjukkan bahwa variabel lokasi (X2) berpengaruh secara positif dan signifikan terhadap loyalitas pelanggan (Y).

3. Kualitas pelayanan dan lokasi berpengaruh terhadap loyalitas pelanggan.

Hasil dari perhitungan yang dilakukan menunjukkan bahwa nilai signifikan variabel independen kualitas pelayanan (X1), dan lokasi (X2) sebesar 0,000 < 0,05 dan 112,899 (F hitung) > 3,04 (F tabel) menunnjukkan bahwa kedua variabel independen kualitas pelayanan (X1) dan lokasi (X2) bersama-sama berpengaruh signifikan terhadap Loyalitas pelanggan hotel bintang dua di Kota Batam.

\section{Simpulan}

Berdasarkan hasil dari pengujian dan pembahasan yang telah diuraikan lengkap pada bab sebelumnya, peneliti menarik kesimpulan penelitian ini sebagai berikut:

1. Kualitas pelayanan berpengaruh terhadap loyalitas pelanggan hotel bintang dua di kota Batam

2. Lokasi berpengaruh terhadap loyalitas pelanggan hotel bintang dua di Kota Batam

3. Kualitas pelayanan dan lokasi berpengaruh terhadap loyalitas pelanggan hotel bintang dua di Kota Batam

\section{DAFTAR PUSTAKA}

Dharmmesta, B. . (n.d.). Azas Azas dan Philosofi Marketing Modern, BPFE, Yogyakarta.

Kotler dan Amstrong. (2011). Marketing Management International, 5th Prentice Hall. Upper Sadle River. New Jersey.

Sanusi. (2011). Metode Penelitian Bisnis,.

Sanusi, A. (2012). Metodologi Penelitian Bisinis. salemba empat.

Sugiyono. (2012). Metode penelitian kuantitatif,kualitatif dan R\&D. ALFABETA.

Sugiyono. (2014). Metode Penelitian Pendidikan Pendekatan Kuantitatif, Kualitatif, dan $R \& D$.

Sugiyono. (2015). Metode Penelitian Kombinasi (Mix Methods).

Tjiptono, F. (2008). Segmenting Pasar Sasaran Potensial. Ghalia Jakarta.

Wibowo, A. E. (2013). SPSS dalam Perspektif dan Riset Bisnis. Penerbit Gava Media, Yogyakarta. 2.

Wibowo, A. E. (2017). Analisis Faktor Faktor yang Mempengaruhi Behavioral Intention. Rekaman, 1, 74-88.

Widjaja, A. (2009). Strategi Penentuan Lokasi dan Penetrasi Pasar Tradisional, Graha Ilmu Yogyakarta. 